\title{
ECR Ion Source Developments at the Oak Ridge National Laboratory
}

\author{
Y. Liu, G. D. Alton, and F. W. Meyer \\ RECEIVED \\ JAN 221999 \\ Physics Division, Oak Ridge National Laboratory, P. O. Box 2008, Oak Ridge, Tennesqe $3784-6368$
}

\begin{abstract}
New techniques for enhancing the performances of electron cyclotron resonance (ECR) ion sources are being investigated at the Oak Ridge National Laboratory. We have utilized the multiple discrete frequency technique to improve the charge state distributions extracted from conventional magnetic field geometry ECR source by injecting three frequencies into the source. A new flat central magnetic field concept, has been incorporated in the designs of a compact allpermanent-magnet source for high charge-state ion beam generation and a compact electromagnetic source for singly ionized radioactive ion beam generation for use in the Holifield Radioactive Ion Beam Facility (HRIBF) research program. A review of the three frequency injection experiments and descriptions of the design aspects of the "volume-type" ECR ion sources will be given in this report.
\end{abstract}

\section{INTRODUCTION}

In recent years, considerable progress has been made in electron cyclotron resonance (ECR) ion source technology in terms of their capabilities for generating high-charge-state ion beams as well as total beam intensities. ECR ion sources are being widely used for the production of highly charged ion beams for heavy ion accelerator based fundamental and applied research. Efforts are under way at the Holifield Radioactive Ion Beam Facility (HRIBF) to develop high performance ECR ion sources for the generation of radioactive ion beams (RIBs). In conventional minimum-B ECR ion sources, narrow bandwidth, single frequency microwave radiation produces thin annular, ellipsoidal-shaped ECR surfaces which constitute a small percentage of the plasma volume and consequently, the efficiency of RF power coupling is limited by the sizes of the ECR surfaces in these sources. It has been suggested that the performances of ECR ion sources can be significantly improved by injecting multiple-discrete or broadband microwave radiation into conventional minimum-B ECR ion sources $(1,2)$ or by tailoring the central region of the magnetic field so that it is resonant with single frequency microwave radiation (3-5). With multiple discrete frequency microwave radiation simultaneously launched into a minimum-B ECR ion source, one can generate multiple, separated and nested ECR heating surfaces. Consequently, more RF power can be coupled into the plasma, thus, heating a much larger electron population to higher energies, the effect of which is to produce higher 


\section{DISCLAIMER}

This report was prepared as an account of work sponsored by an agency of the United States Government. Neither the United States Government nor any agency thereof, nor any of their employees, make any warranty, express or implied, or assumes any legal liability or responsibility for the accuracy, completeness, or usefulness of any information, apparatus, product, or process disclosed, or represents that its use would not infringe privately owned rights. Reference herein to any specific commercial product, process, or service by trade name, trademark, manufacturer, or otherwise does not necessarily constitute or imply its endorsement, recommendation, or favoring by the United States Government or any agency thereof. The views and opinions of authors expressed herein do not necessarily state or reflect those of the United States Government or any agency thereof. 


\section{DISCLAIMER}

Portions of this document may be illegible in electronic image products. Images are produced from the best available original document. 
charge-state distributions and high intensities within a particular charge state than possible with single-frequency heating. The multiple-frequency method was first demonstrated by Xie and Lyneis (2) by injecting two frequency microwave radiation, well separated in frequency, into the LBNL AECR ion source to enhance the production of highly charged $\mathrm{Bi}$ and $\mathrm{U}$ ions. They have shown that multiple discrete frequency heating also improves the plasma stability, which benefits the production of highly charged ions (6) as predicted in Ref. (5). We have successfully utilized two- and three-frequency plasma heating in the Oak Ridge National Laboratory (ORNL) Caprice ECR ion source (7) to improve the high charge state distributions extracted from the source (8).

An alternative to the multiple-frequency technique has been proposed (3-5) that employs a new magnetic field configuration which has an extended central flat region tuned to be in resonance with single-frequency microwave radiation. Because of the extended resonant plasma volume, significantly more $R F$ power can be coupled into the plasma, resulting in heating of electrons over a much larger volume than is possible in conventional ECR ion sources. The ability to ionize a larger fraction of the particles in the plasma volume effectively reduces the probability of resonant and non-resonant charge exchange, thereby increasing the residence time of an ion in a given charge state and the probability for subsequent and further ionization. All other parameters being equal, the "volume" ECR source should result in higher charge-state distributions, higher beam intensities, and improved operational stability (1). We are presently fabricating a compact, all-permanent-magnet volume-type ECR ion source that incorporates the flatfield concept for high charge-state ion beam generation. A compact electromagnetic volume-type ECR ion source has also been designed for singly charged radioactive ion beam generation for the HRIBF research program. The results derived from the multifrequency plasma heating experiments and the design details of an all permanent-magnet volume-type ECR ion source for multiply charged ion beam generation as well as those for a volume-type ECR ion source for low charge-state RIB generation will be described in this report.

\section{MULTI-FREQUENCY MICROWAVE PLASMA HEATING}

We have conducted comparative studies to assess the relative performance of the ORNL Caprice ECR ion source for the production of multiply charged ion beams when excited with one, two and three-frequency microwave radiation. The ORNL Caprice ECR ion source (7) is equipped with a solenoidal minimum-B axial magnetic field and a hexapole cusp radial magnetic field for confining the plasma in a multi-mode cavity. The normal operating frequency for the source is $10.6 \mathrm{GHz}$, supplied by a klystron, coupled into the cavity through a coaxial waveguide injection system. In order to simultaneously inject three frequencies into the plasma chamber of the source, it was found necessary to design and fabricate an appropriate waveguide/injection system to avoid cross coupling of 


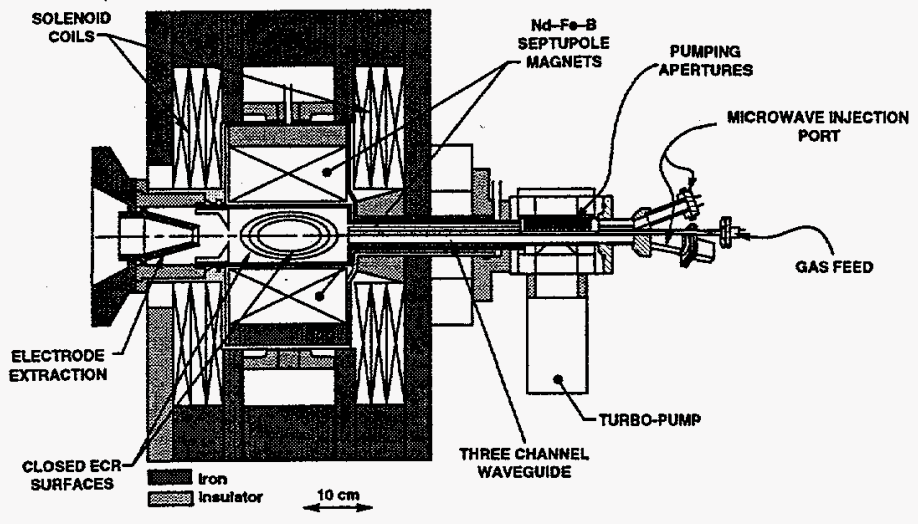

Fig. 1. ORNL-DWG 97-100794. Schematic Drawing of the ORNL Caprice ECR ion source equipped with a three-frequency microwave injection system. the radiation in the waveguide system. The ORNL Caprice source, equipped with the new three-frequency injection module, is shown in Fig. 1. Microwave radiation between 10 and $14 \mathrm{GHz}$ can be injected into the source. The studies were conducted with the existing $10.6 \mathrm{GHz}, 1 \mathrm{~kW}$, klystron power supply and two TWT-based microwave power supplies with rated powers of 80 and $200 \mathrm{~W}$, respectively.

The charge state distributions and ion beam intensities within a particular charge state for $\mathrm{Ar}$ and $\mathrm{Xe}$ feed gases were measured by injecting multiple discrete-frequency microwave radiation into the source. For all the measurements, the $1 \mathrm{~kW}, 10.6 \mathrm{GHz}$ microwave power supply was used to saturate the charge-state distributions for $\mathrm{Ar}^{\mathrm{q}}$ $(132 \mathrm{~W})$ and $\mathrm{Xe}^{\mathrm{q}^{+}}(290 \mathrm{~W})$ before adding the other frequencies. Fig. 2 shows intensity versus charge state for $\mathrm{Ar}^{\mathrm{q}^{+}}$obtained individually with $10.6 \mathrm{GHz}(132 \mathrm{~W})$ and $11.57 \mathrm{GHz}$ $(50 \mathrm{~W})$ microwave radiation, and with both frequencies in combination $[10.6 \mathrm{GHz}(132$ W) $+11.57 \mathrm{GHz}(50 \mathrm{~W})]$. The corresponding chargestate distribution is displayed in Fig. 3. We note that the charge-state distributions resulting from $10.6 \mathrm{GHz}$ or $11.57 \mathrm{GHz}$ single-frequency heating were almost identical, while the charge-state distribution from two-frequency heating is clearly different; the highcharge states are seen to increase while the low-charge states decrease, even through the most probable charge state remains the same. The intensities of $\mathrm{Ar}^{\mathrm{q}^{+}}$with charge states higher than the most probable $(\mathrm{q}=8)$ were increased by $\sim 2$ over those

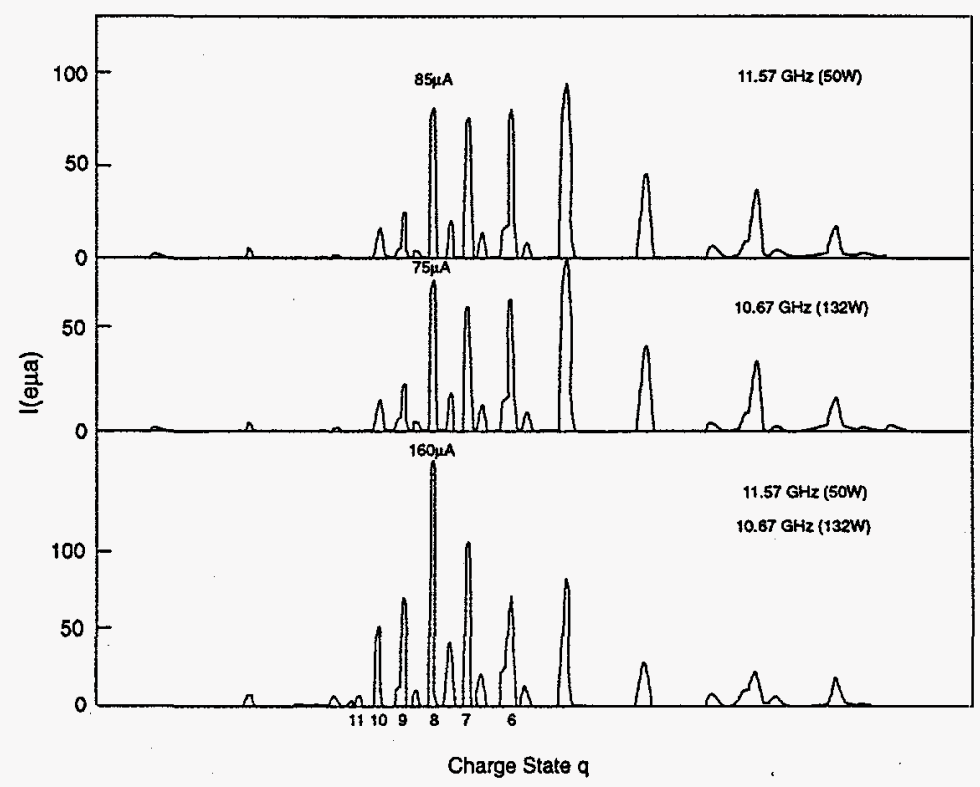

Fig. 2. ORNL-DWG 97-100716. Intensity vs. charge state for $A r^{8}$ ion beams extracted from the ORNL Caprice ECR ion Source. Upper curve: 50 W of $11.57 \mathrm{GHz}$ TWT power (nonoptimized); middle curve: $132 \mathrm{~W}$ of 10.6 $\mathrm{GHz}$ klystron power (optimized); and lower curve: $132 \mathrm{~W}$ of $10.6 \mathrm{GHz}$ klystron power (optimized) plus $50 \mathrm{~W}$ of $11.57 \mathrm{GHz}$ TWT power (nonoptimized). 


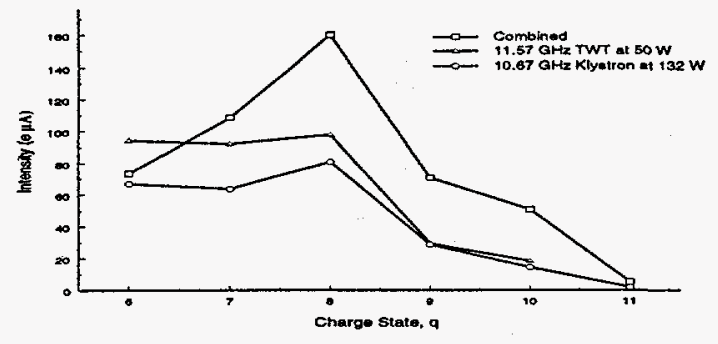

Fig. 3. ORNL-DWG 97-123882. Charge-state distributions for $\mathrm{Ar}^{\mathrm{q}+}$; lower curve: generated with $132 \mathrm{~W}$ of $10.67 \mathrm{GHz}$ klystron power (optimized); middle curve: generated with 50 W of $11.59 \mathrm{GHz}$ TWT power (nonoptimized); and upper curve: generated with a combination of $132 \mathrm{~W}$ of $10.67 \mathrm{GHz}$ klystron power (optimized) and $50 \mathrm{~W}$ of $11.57 \mathrm{GHz}$ TWT power (nonoptimized). when only single-frequency klystron microwave power was used.

One, two and three-frequency heating experiments were also conducted with $\mathrm{Xe}$ feed gas with 10.6 $\mathrm{GHz}(290 \mathrm{~W}), 10.6 \mathrm{GHz}(290 \mathrm{~W})+$ $11.57 \mathrm{GHz}(40 \mathrm{~W})$ and $10.6 \mathrm{GHz}$ $(290 \mathrm{~W})+11.57 \mathrm{GHz}(40 \mathrm{~W})+12$ $\mathrm{GHz}(52$ W) microwave power. Because of power supply limitations, we were unable to optimize the ion source performance for the cases of two- and three-frequency heating. Fig. 4 shows the Xe charge-state distribution produced when the source was operated with one, two and three frequency microwave radiation, respectively. It is clear that with the addition of the second and third frequencies, the most probable $\mathrm{Xe}^{\mathrm{q}^{+}}$ charge state moves to higher values by one unit and the intensities for the high-charge states are increased by $\sim 3$ over those for the saturated, single-frequency $10.6 \mathrm{GHz}(290$ W) case. Although maximum intensities from the source could not be obtained because of problems with the TWT power supplies, our results clearly illustrate that the performance of conventional geometry ECR ion sources can be significantly improved by use of multiple-discrete frequency plasma heating.

\section{DESIGN FEATURES OF AN ALL-PERMANENT MAGNET VOLUME ECR ION SOURCE}

A compact, all-permanent magnet, single-frequency ECR ion based on a novel magnetic field configuration has been designed and is presently under construction (9). The source is designed to achieve a large, onaxis ECR "volume," which allows ECR power to be efficiently coupled about and along the axis of symmetry. A

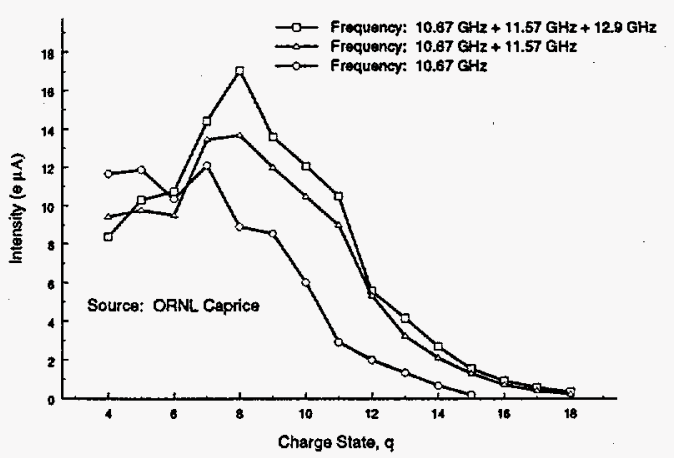

Fig. 4. ORNL-DWG 97-123883. Charge-state distributions for Xe ion beams extracted from the ORNL Caprice ECR ion source equipped with a three-frequency microwave injection system; lower curve: $290 \mathrm{~W}$ of $10.6 \mathrm{GHz}$ kylstron power (optimized); middle curve: $290 \mathrm{~W}$ of 10.6 $\mathrm{GHz}$ klystron power (optimized) and $40 \mathrm{~W}$ of $11.59 \mathrm{GHz}$ TWT power (nonoptimized); and upper curve: combination of $290 \mathrm{~W}$ of $10.6 \mathrm{GHz}$ klystron power (optimized), $40 \mathrm{~W}$ of $11.57 \mathrm{GHz}$ TWT power (nonoptimized), and $52 \mathrm{~W}$ of $12.9 \mathrm{GHz}$ TWT power (nonoptimized). 


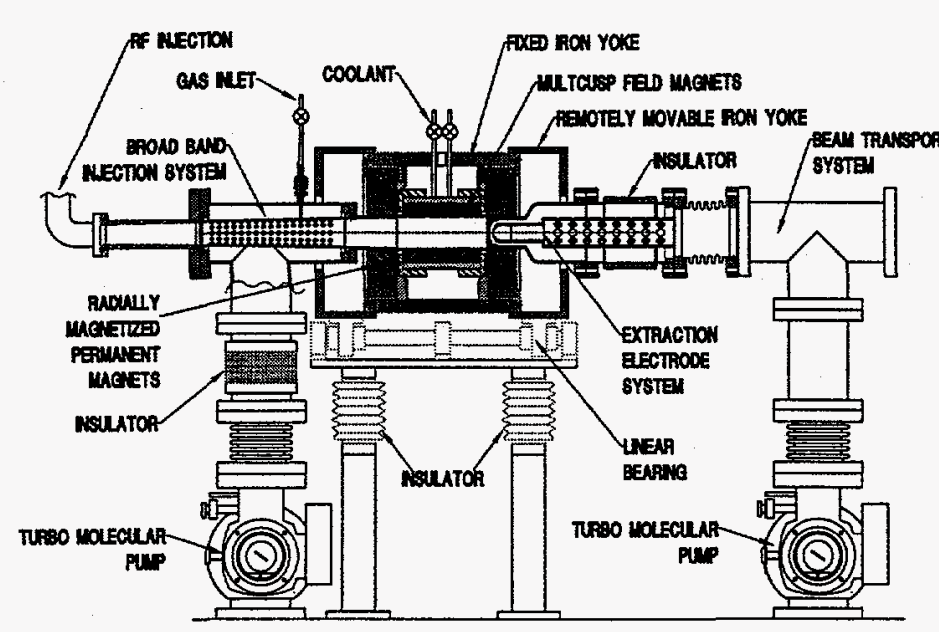

Fig. 5. Schematic view of the flat- $B$ ECR ion source.

schematic representation of the source is illustrated in Fig. 5 and the axial magnetic field is displayed in Fig. 6. As noted, the axial magnetic field profile is flat (constant mod-B) in the center which extends over the length of the central field region along the axis of symmetry and radially outward to form a uniformly distributed ECR plasma "volume". This magnetic field design strongly contrasts with those used in conventional ECR ion sources where the central field regions are approximately parabolic and the consequent ECR zones are "surfaces". According to computational studies (3) the new configuration will result in dramatic increases in the absorption of RF power, thus enabling the heating of electrons over a much larger volume, thereby increasing the electron temperature and "hot" electron population in the plasma. The axial mirror field is produced by two, $50-\mathrm{mm}$ thick, annular $\mathrm{NdFeB}$ permanent magnets radially magnetized in opposite directions and separated by $\sim$ $150 \mathrm{~mm}$. Specially designed and positioned iron cylinders are used to create the flat central field region between the mirror magnets. The source is designed to operate at a central frequency of $\sim 6 \mathrm{GHz}$ and the flat magnetic field region can be adjusted by mechanical means to tune the source to the resonance condition within the limits of 5.6 to $6.9 \mathrm{GHz}$. The plasma confinement magnetic field mirror has a ratio $\mathrm{B}_{\max } / \mathrm{B}_{\mathrm{ECR}}$ of slightly greater than two.

Since the radial magnetic $\stackrel{N}{\oplus}$ field distribution is proportional to $\mathrm{B}=\mathrm{B}_{0} \mathrm{r}^{\mathrm{N} / 2-1}$ where $\mathrm{N}$ is the number of cusps, $\mathrm{r}$ is the radial distance from the center of the device to the tip of the magnet, a highorder multicusp field for confining the plasma in the radial direction can increase the

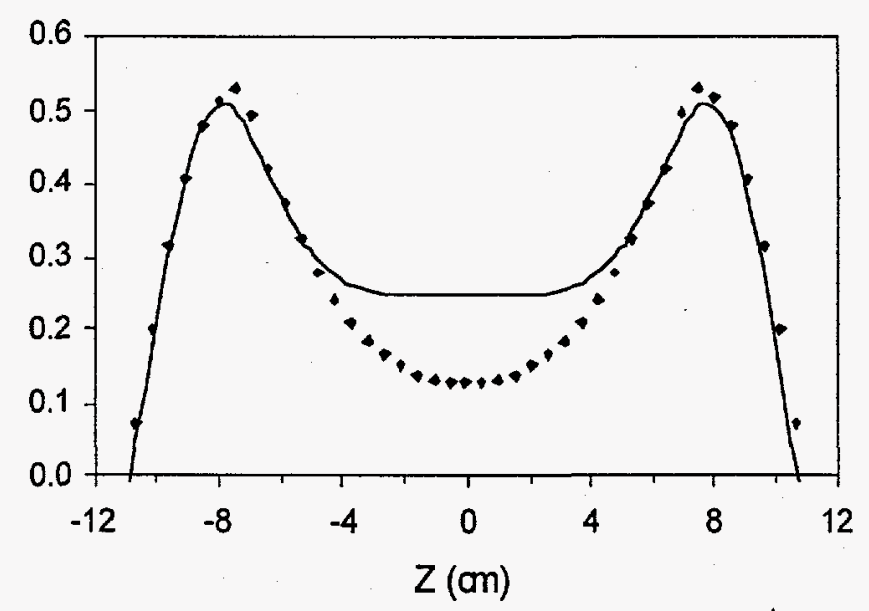

Fig. 6. Axial magnetic field profiles of the volume" (solid line) and conventional minimum- $B$ configuration "surface" (dotted line) ECR ion sources. 
resonant volume in the radial direction. Therefore, instead of a sextupole field, commonly used in conventional minimum-B ECR ion sources, a 12-pole multicusp field was designed for the new source. Twelve $\mathrm{NdFeB}$ bar magnets, equally spaced in an alternating polarity arrangement around the circumference of a $57.2-\mathrm{mm}$ diameter, water cooled $\mathrm{Cu}$ magnet holder, are used to produce the desired field for radial confinement, as shown in Fig. 7. In combination with the axial mirror field, a magnetic field strength of $5.1 \mathrm{kG}$, approximately equal to that of the axial mirror field, is generated at the inner wall of the plasma chamber. For comparison, the radial field profile for a sextupole configuration $(\mathrm{N}=6)$ is also plotted in Fig. 7. As noted, the region over which the field region is uniform is much greater for the $\mathrm{N}=12$ multicusp field.

The cylindrical cavity plasma chamber is made of $\mathrm{Al}$ and is $15.6 \mathrm{~cm}$ in length and 5.4 $\mathrm{cm}$ in diameter. Computational design studies were performed for several different $\mathrm{RF}$ injection schemes, using the finite element code ANSYS (10). A broadband RF injection system was then selected for the new ion source. It is a long, precisely tapered rectangular-to-circular transition section, starting from a rectangular WR137 waveguide and ending with a circular diameter that matches the dimension of the plasma chamber. The transition from rectangular to circular is very smooth so that it has excellent voltage standing wave ratio (VSWR) while converting the rectangular waveguide $\mathrm{TE}_{10}$

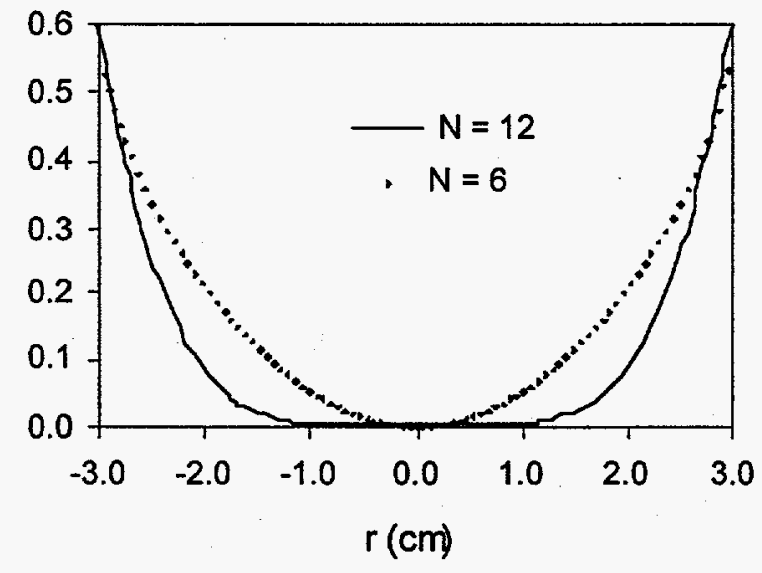

Fig. 7. Comparison of $N=6$ and $N=12$ cusp radial magnetic field profiles. The effect of increasing the number of cusps from $N=6$ to $N=12$ is apparent: the lower order multiple field results in a much smaller resonant plasma volume.

dominant mode to the dominant

circular waveguide $T E_{1 n p}$ eigenmodes with the $R F$ power concentrated in the resonant plasma volume and the E-vector oriented perpendicular to the magnetic field direction for efficient electron heating. The mechanical design of the source is very flexible in that it can be converted from a "volume" source to a "surface" source and vice-versa by simply adding/removing a $\mathrm{Fe}$ ring to/from the central region between the mirror magnets. The resulting minimum-B axial magnetic field profile, after adding the $\mathrm{Fe}$ ring, is also shown in Fig. 6. The multicusp field can also be changed to an $\mathrm{N}=6$ field distribution when the source is configured as a conventional "surface" source. Comparisons will be made of the performances of the "volume" and conventional single-frequency "surface" ECR sources in terms of the charge-state distributions and intensities within a particular charge-state for each configuration. 


\section{A COMPACT VOLUME ECR ION SOURCE FOR RIB APPLICATIONS}

The HRIBF at the Oak Ridge National Laboratory is an on-line isotope separator (ISOL) facility for the production, generation, and post acceleration of radioactive ion beams for nuclear physics and nuclear astrophysics research. Radioactive nuclei produced in the target by the ISOL technique are transferred to the appropriate ion source where they are ionized and injected into the accelerator. Since many chemically active radioactive species are released from the target in molecular form, an ion source that can simultaneously dissociate molecules and efficiently ionize their atomic constituents is highly desirable. Compared to other ion sources, the ECR ion source is the best choice for the efficient formation of ions from gaseous and volatile compounds. The source has proved to be a very efficient means for dissociating and ionizing members of traditionally difficult gaseous molecular species such as $\mathrm{H}_{2}$ and $\mathrm{CO}$, etc. $(11,12)$.

A compact volume ECR ion source operating at $2.45 \mathrm{GHz}$ has been designed and will be developed for use at the HRIBF for the generation of RIBs. We believe that the volume-type ECR ion source offers the prospect of high yields of low charge-state radioactive ion beams with good emittance and low energy spread because of the fact that the ions are formed in close proximity to the optical axis of the source, thus can be more efficiently extracted without having to pass through an extended region of strong radially directed magnetic field. Since negative ions beams are required for injection into the 25 MV tandem accelerator that is used for post acceleration of RIBs for the HRIBF research program at ORNL, the source will be optimized for the generation of low charge-state positive RIBs as required for efficient charge exchange conversion to negative ion beams. The source should also be simple, reliable, and inexpensive with long operating lifetime. These guidelines have led us to the design of the simple electromagnetic ECR source illustrated in Fig. 8. The axial magnetic mirror field is produced with mirror coils and trim coils in combination with properly arranged ion yokes. The trim coils are driven in an opposite direction to those of the mirror coils. When the currents in the trim coils are adjusted properly, the resultant field is very uniform with magnitude of $875 \mathrm{G}$, corresponding to the ECR condition for $2.45 \mathrm{GHz}$ microwave radiation. The axial field profile for the source is shown in Fig. 9. The mirror field is designed to have a small mirror ratio of $\sim 1.2$ at the ion extraction end and a high mirror ratio of $\sim 2$ on the RF injection end of the source. The cylindrical plasma chamber is made of $\mathrm{Ta}$ and is about 18 $\mathrm{cm}$ in length and $7.6 \mathrm{~cm}$ in diameter. Ta is used because of the high temperatures required to effect fast diffusion from target materials. Proton beams from the ORIC will pass through the plasma chamber at a right angle with respect to the ion extraction axis, as shown, and interact with target materials diametrically opposed. This arrangement provides direct coupling of the radioactive species to the plasma chamber following their diffusion release from the target material. 


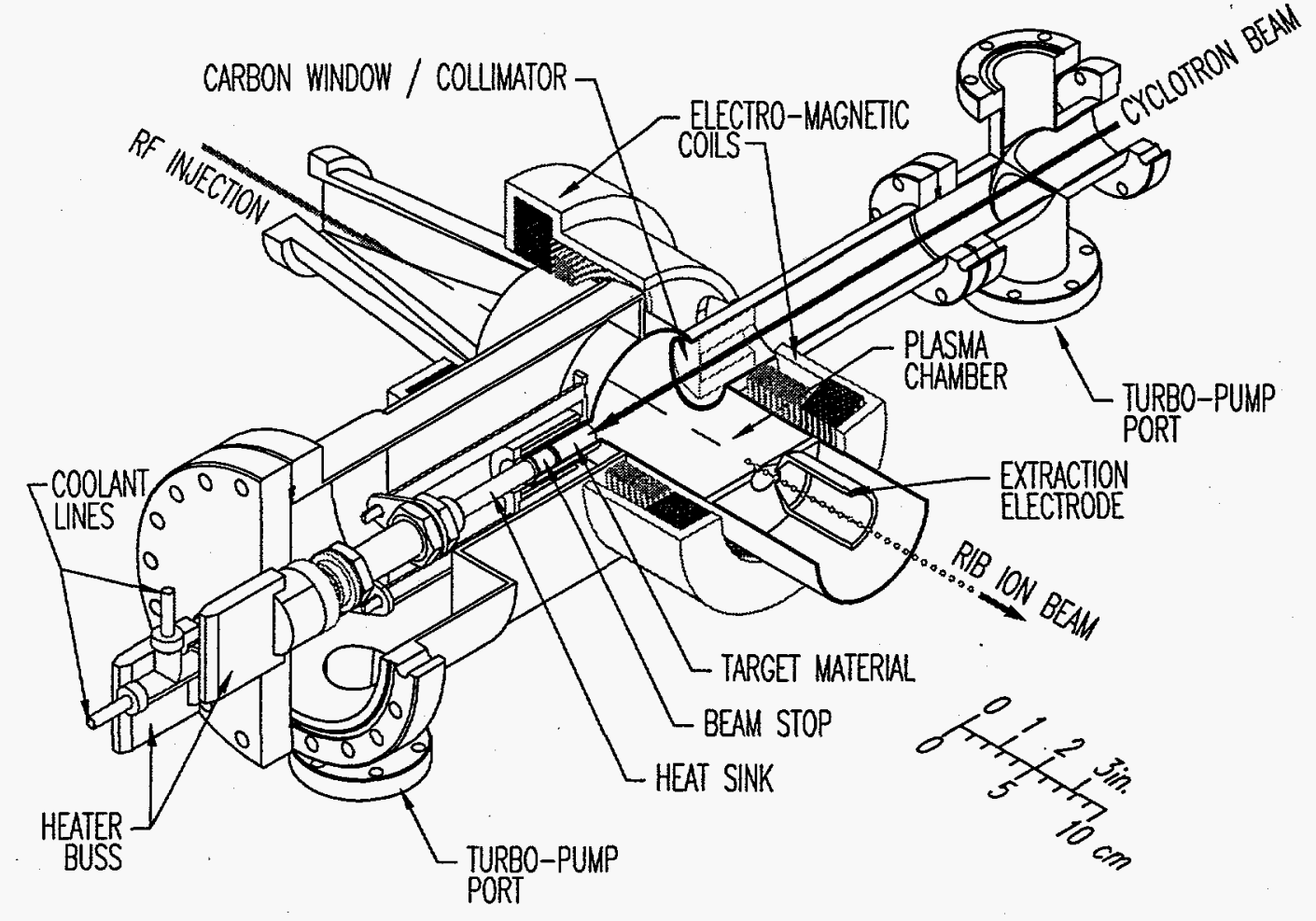

Fig. 8. Isometric drawing of the $2.45 \mathrm{GHz} E C R$ ion source for the generation of RIBs.

No multicusp magnetic field will be used for plasma confinement in the radial direction. This makes the source much simpler, less expensive and durable for RIB applications by avoiding the use of permanent magnets that are subject to neutron degradation. An ECR plasma source has been developed that does not have radial plasma confinement and exhibits high degrees of molecular

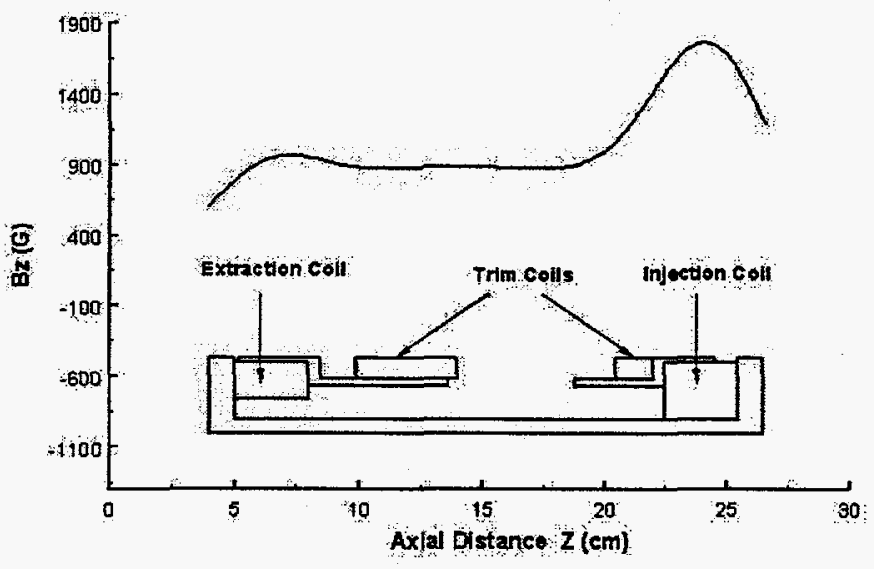

Fig. 9. Schematic layout of mirror and trim coils and the axial magnetic field profile for the $2.45 \mathrm{GHz}$ volume $\mathrm{ECR}$ ion source. dissociation and high intensities for the production of singly charged ion beams $(12,13)$.

\section{ACKNOWLEDGMENTS}

Research at the Oak Ridge National 'Laboratory is supported by the U.S. Department of Energy under contract DE-AC05-96OR22464 with Lockheed Martin Energy Research Corp. 


\section{REFERENCES}

1. Alton, G. D., Proc. of the 14th Int. Conference on Cyclotrons and their Applications, ed. J. C. Cornell (Capetown, South Africa, October 8-13, 1995), World Scientific, Singapore, p. 362.

2. Xie, Z. Q. and Lyneis, C. M. in Proc. of the 12th Int. Workshop on ECR Ion Sources (Wakoshi, Japan, April 25-27, 1995), eds. M. Sekiguchi and T. Nakagawa, INS-J-182 (1995) 24.

3. Alton, G. D., and Smithe, D. N., Rev. Sci. Instrum. 65 (1994) 775.

4. Alton, G. D., Nucl. Instr. and Meth. A 382 (1996) 276.

5. Alton, G. D., and Smithe, D. N., Physica Scripta T71 (1996) 66.

6. Xie, Z. Q., Rev. Sci. Instrum. 69 (1998) 625.

7. Jacquot, B. and Pontonnier, M., Nucl. Instr, and Meth. A 287 (1990) 341.

8. Alton, G. D., Meyer, F. W., Liu, Y., Beene, J. R., and Tucker, D., Rev. Sci. Instrum. 69 (1998) 2305.

9. Liu, Y., Alton, G. D., Mills, G. D., Reed, C. A., and Haynes, D. L., Rev. Sci. Instrum. 69 (1998) 1311.

10. ANSY is a finite element code marketed by ANSYS, Inc., Cannonsburg; PA 15317, USA.

11. Xie, Z. Q., Cerny, J., Guo, F. Q., Joosten, R., Larimer, R. M., Lyneis, C. M., McMahan, P., Norman, E. B., O'Neil, J. P., Powell, J., Rowe, M. W., VanBrocklin, H. F., Wutte, D. and Xu, X. J., The 8th International Conference on Heavy-Ion Accelerator Technology, October 5-9, 1998, Argonne, IL, USA (these proceedings).

12. Schneider, R. J., Von Reden, K. F., Wills, J. S. C., Diamond, W. T., Lewis, R., Savard, G., and Schmeing, H., Nucl. Instr. and Meth. B 123 (1997) 546.

13. Wills, J. S. C., Lewis, R. A., Diserens, J., Schmeing, H., and Taylor, T., Rev. Sci. Instrum. 69 (1998) 65. 